\title{
PHẪU THUẬT ĐIỀU TRI KÊNH NHĨ THẤT TOÀN PHẦN \\ TẠI BỆNH VIỆN TRUNG ƯƠ'NG HUẾ
}

Nguyêen Xuân Hùng*, Nguyễn Đúc Dũng*, Trần Hoài Ân*, Đinh Trần Nguyên Vữ ${ }^{*}$ Bùi Đức An Vinh*

Nghiên cứu hồi cứu tất cả bệnh nhân được phẫu thuật kênh nhĩ thất toàn phần tại bệnh viện Trung U’ơng Huế từ 1/2016 đến 1/2018. Có 52 bệnh nhân được phẫu thuật kênh nhĩ thất toàn phần trong thời gian nghiên cứu, độ tuổi trung bình là $1,12 \pm 0,26(0,15-3)$. Đa số bệnh nhân có bị hội chứng Down (76,9\%). Tổn thương van nhĩ thất trước và sau mổ có cải thiện rõ rệt, áp lực động mạch phổi giảm nhiều, 3 bệnh nhân $(5,8 \%)$ bị block A-V độ III phải đặt máy tạo nhịp, tỷ lệ tử vong sớm 4/52 (7,7\%). Cần phải có các phương tiện chính xác để phân loại bệnh tốt và lựa chọn đúng phương pháp phẫu thuật để cho kết quả tốt. Phẫu thuật điều kênh nhĩ thất toàn phần cho kết quả tốt.

Từ khóa: kênh nhĩ thất toàn phần.

\section{SUMMARY}

TREATMENT OF COMPLETE

ATRIOVENTRICULAR SEPTAL DEFECT IN HUE CENTRAL HOSPITAL

All patients underwent operated complete AVSD at Hue Centre hospital from january 2016 to january 2018.52 patients, the mean age: $1,12 \pm$ $0,26(0,15-3)$. Down syndrome included: 40 case (76,9\%). Atrioventricular valve after operative showed marked improvement, pulmonary artery pressure tended to decrease when compared with preoperative, postoperative arrhythmias: Three cases with BAV III to permanent pacing $(5,8 \%)$. Early mortality 4/52(7,7\%). Good diagnosis and surgery in right time bring the good result. Surgical complete AVSD give good results.

Keywords: Complete Atrioventricular Septal Defect (AVSD)

\section{I. ĐẠTT VẤN ĐỀ}

Kênh nhĩ thất toàn phần là một bệnh lý tim bẩm sinh phức tạp với các đặc trưng như: thông liên nhĩ lỗ thứ nhất, thông liên thất rộng không hạn chế và tổn thương van nhĩ thất nặng. Van hai lá và ba lá không có sự phân chia rõ rệt, nó có chung một vòng van. Can thiệp phẫu thuật sớm kênh nhĩ thất toàn phần đã trở thành phương pháp điều trị được lựa chọn ở nhiều trung tâm. Xu hướng này đã góp phần làm giảm tỷ lệ tử vong sau phẫu thuật gần đây [2], [6], [7]. Trong thời gian gần đây phẫu thuật điều trị kênh nhĩ thất toàn phần đã có nhiều phát triển nhưng vẫn là một thách thức lớn đối với các phẫu thuật viên tim mạch. Nghiên cứu này thực hiện để xác định yếu tố lâm sàng, cận lâm sàng và kết quả phẫu thuật ở những bệnh nhân phẫu điều trị teo van phổi kèm thông liên thất tại bệnh viện Trung Ương Huế.

\section{II. ĐỐI TƯợNG VÀ PHƯƠNG PHÁP NGHIÊN CÚU}

2.1. Đối tượng nghiên cứu: 52 bệnh nhân được phẫu thuật điều trị teo van phổi kèm thông liên thất từ tháng $1 / 2016$ đến $1 / 2018$.

Bệnh nhân kênh nhĩ thất toàn phần kèm tim một thất bị loại khỏi nghiên cứu.

\subsection{Phương pháp nghiên cứu:}

\subsubsection{Thiết kế nghiên cứu: Nghiên cứu} hồi cúu.

Bệnh nhân được khám, chẩn đoán và phẫu thuật tại Trung tâm Tim mạch-Bệnh viện Trung Uơng Huế.

* Khoa Ngoại lồng ngưcc, tim mạch - Bệnh viện Trung Uơng Huế Nguời chịu trách nhiệm khoa họ: ThS. Nguyễn Xuân Hùng Ngày nhận bài: 01/05/2018 - Ngày Cho Phép Đăng: 20/05/2018 Phản Biện Khoa học: PGS.TS. Đặng Ngọc Hùng GS.TS. Lê Ngoc Thành 


\subsubsection{Nội dung nghiên cứu:}

- Đặc điểm chung: tuổi, giới, hội chứng down.

- Bệnh lý tim mạch khác kèm theo.

- Đặc điểm siêu âm tim: Đánh giá mức độ hở van nhĩ thất, áp lực động mạch phổi.

- Đặc điểm trong mổ: thời gian tuần hoàn ngoài cơ thể, thời gian liệt tim.

- Thông số sau mổ: Hở van nhĩ thất sau mổ, áp lực động mạch phổi sau mổ.
- Đặc điểm thời gian nằm hậu phẫu, thời gian ra viện.

\section{KẾT QUẢ NGHIÊN CÚU}

\section{1. Đặc điểm chung.}

- Tỷ lệ nam / nữ: 24/28

- Tuổi: Độ tuổi trung bình là: 1,12士0,26 trong đó thấp nhất 2 tháng và lớn nhất là 3 tuổi. Đa số bệnh nhân $<6$ tháng tuổi $(80,8 \%)$.

Đa số bệnh nhi bị hội chứng Down: 40 bệnh $(76,9 \%)$.

\subsection{Bệnh lý tim mạch khác kèm theo.}

Nghiên cứu đã ghi nhận được các bệnh lý tim mạch kèm theo trên bệnh nhân bị kênh nhĩ thất toàn phần, thể hiện trong bảng dưới đây.

\section{Bảng 3.1. Một số bênh lý tim mạch kèm theo.}

\begin{tabular}{|l|c|c|}
\hline Bệnh lý tim mạch khác kèm theo & $\mathrm{n}$ & $\%$ \\
\hline Lỗ thông liên nhĩ thứ phát & 24 & 46,2 \\
\hline Còn ống động mạch & 38 & 73,1 \\
\hline Hẹp eo động mạch chủ & 5 & 9,6 \\
\hline Hẹp động mạch phổi & 3 & 5,8 \\
\hline Tứ chứng fallot & 1 & 1,9 \\
\hline Tĩnh mạch phổi trở về bất thường & 2 & 3,8 \\
\hline
\end{tabular}

Bệnh nhân kênh nhĩ thất toàn phần thường kèm theo các dị tật như còn ống động mạch $(73,1 \%)$ và có lỗ thông liên nhĩ thứ phát $(46,2 \%)$

\subsection{Siêu âm}

\subsubsection{Múc độ hở van trước mổ.}

Bảng 3.2. Mức độ hở van trước mổ.

\begin{tabular}{|c|c|c|}
\hline Mức độ hở van & Van hai lá & Van ba lá \\
\hline$<2 / 4$ & 9 & 10 \\
\hline $2-3 / 4$ & 38 & 36 \\
\hline$>3 / 4$ & 5 & 6 \\
\hline $\mathrm{n}$ & 52 & 52 \\
\hline
\end{tabular}

Mức độ hở van nhĩ thất trước mổ chủ yếu là trung bình và nặng từ $2 / 4$ trở lên. Trong đó hở van hai lá $(82,7 \%)$ và van ba lá $(80,7 \%)$ cho thấy vấn đề phải phẫu thuật sớm để tránh tình trạng hở van tiến triển và khó sữa chữa. 


\subsubsection{Ap lục động mạch phổi trước mổ.}

Bảng 3.3. Áp lực động mạch phổi trước mổ.

\begin{tabular}{|l|c|c|}
\hline Áp lực động mạch phổi & $\mathrm{n}$ & $\%$ \\
\hline$<30 \mathrm{~mm} \mathrm{Hg}$ & 2 & 3,8 \\
\hline $30-60 \mathrm{~mm} \mathrm{Hg}$ & 15 & 28,9 \\
\hline$>60 \mathrm{~mm} \mathrm{Hg}$ & 35 & 67,3 \\
\hline
\end{tabular}

Hầu hết các bệnh nhân đều có tăng áp phổi (96,2\%), trong đó có đến 35 bệnh nhi có tăng áp phổi rất nặng $>60 \mathrm{~mm} \mathrm{Hg}(67,3 \%)$. Cho thấy mức độ nặng của bệnh cũng như sự cần thiết phải phẫu thuật sớm tránh những biến chứng của tăng áp phổi.

\subsubsection{Phân loại type kênh nhĩ thất toàn phần theo Rastelli.}

Bảng 3.4. Phân loại type kênh nhĩ thất toàn phần theo Rastelli.

\begin{tabular}{|l|c|c|}
\hline Type & $\mathrm{n}$ & $\%$ \\
\hline Rastelli A & 41 & 78,8 \\
\hline Rastelli B & 11 & 21,2 \\
\hline Rastelli C & 0 & 0 \\
\hline
\end{tabular}

Bệnh nhân chủ yếu vào viện vì kênh nhĩ thất type $\mathrm{A}(78,8 \%)$ và không có bệnh nhi nào được chẩn đoán type $\mathrm{C}$

\subsection{Phẫu thuật}

\subsubsection{Thò̀i gian tuần hoàn ngoài cơ thể và thò̀i gian liệt tim.}

- Thời gian tuần hoàn ngoài cơ thể: $125,3 \pm 19,5$ phút.

- Thời gian cặp động mạch chủ: 84,3 $\pm 14,2$ phút.

Phẫu thuật kênh nhĩ thất toàn phần thường phải sữa chửa nhiều dị tật nên thời gian tuần hoàn ngoài cơ thể cũng như thời gian cặp động mạch chủ thường kéo dài

\subsubsection{Hở van sau phẫu thuật.}

Bảng 3.5. Mức độ hở van sau phẫu thuật.

\begin{tabular}{|c|c|c|}
\hline Mức độ hở van & Van hai lá & Van 3 lá \\
\hline$<2 / 4$ & 48 & 50 \\
\hline $2-3 / 4$ & 4 & 2 \\
\hline$>3 / 4$ & 0 & 0 \\
\hline $\mathrm{n}$ & 52 & 52 \\
\hline
\end{tabular}

Sau phẫu thuật tình trạng hở van được cải thiện rõ rệt chủ yếu còn hở van mức độ nhẹ 92,3\% đối với van hai lá và $96,2 \%$ với van 3 lá. Không có bệnh nhi nào có tình trạng hở van nặng ở cả van hai lá và van 3 lá.

\subsection{3. Áp lục động mạch phổi sau mổ}

\section{Bảng 3.6. Áp lực động mạch phổi sau mổ.}

\begin{tabular}{|l|c|c|}
\hline Áp lực động mạch phổi & $\mathrm{n}$ & $\%$ \\
\hline$<30 \mathrm{~mm} \mathrm{Hg}$ & 48 & 92,3 \\
\hline $30-60 \mathrm{~mm} \mathrm{Hg}$ & 4 & 7,7 \\
\hline$>60 \mathrm{~mm} \mathrm{Hg}$ & 0 & 0 \\
\hline
\end{tabular}


Bệnh nhi sau phẫu thuật chủ yếu hết tăng áp phổi (92,3\%), có 4 bệnh nhi còn tăng áp phổi trung bình, cả 4 bệnh nhi này đều lớn tuổi nên thời gian hạ áp lực động mạch phổi lâu hơn.

\subsubsection{Biến chúng phẫu thuật.}

Bảng 7. Biến chứng sau mổ.

\begin{tabular}{|l|c|c|}
\hline Biến chứng sau mổ & $\mathrm{n}$ & $\%$ \\
\hline Hội chứng cung lượng tim thấp & 4 & 7,7 \\
\hline Tràn dịch màng tim, màng phổi & 6 & 11,5 \\
\hline Chảy máu sau mố & 3 & 5,8 \\
\hline Suy thận cấp & 7 & 13,5 \\
\hline Block A-V độ III & 4 & 7,7 \\
\hline Tử vong & 5 & 9,6 \\
\hline
\end{tabular}

Các biến chứng thường gặp trong phẫu thuật kênh nhĩ thất toàn phần là cung lượng tim thấp $(7,7 \%)$ suy thận cấp $(11,5 \%)$ cần phải làm thẩm phân phúc mạc trong đó 2 bệnh nhi cải thiện. chảy máu sau mổ cũng là một biến chứng thường gặp $(13,5 \%)$ do thời gian tuần hoàn ngoài cơ thề lâu dẫn đến tình trạng rối loạn chảy máu. Ngoài ra một biến chứng không mong muốn nhất là Block $\mathrm{A}-\mathrm{V}$ độ III cũng xuất hiện ở 4 bệnh nhi (7,7\%).

Tỷ lệ tử vong sau phẫu thuật :9,6\%

\subsubsection{Thời gian hậu phẫu, thời gian nằm viện.}

- Thời gian hậu phẫu: 14,3 $\pm 3,7$ ngày

- Thời gian nằm viện: $21,4 \pm 8,5$ ngày

Phẫu thuật kênh nhĩ thất toàn phần cho kết quả tốt, thời gian hậu phẫu cũng như thời gian nằm viện ngắn.

\subsubsection{Tái khám sau 3, 6 tháng}

Bảng 8. Tái khám sau 36 tháng

\begin{tabular}{|c|c|c|c|}
\hline & & 3 tháng & 6 tháng \\
\hline \multirow{3}{*}{ Hở van hai lá } & $<2 / 4$ & 47 & 47 \\
\cline { 2 - 4 } & $2-3 / 4$ & 1 & 0 \\
\cline { 2 - 4 } & $>3 / 4$ & 0 & 0 \\
\hline \multirow{3}{*}{ Hở van ba lá } & $<2 / 4$ & 48 & 48 \\
\cline { 2 - 4 } & $2-3 / 4$ & 0 & 0 \\
\hline & $>3 / 4$ & 0 & 0 \\
\hline \multirow{3}{*}{ Tăng áp động mạch phổi } & $<30 \mathrm{mmHg}$ & 48 & 48 \\
\hline & $30-60 \mathrm{mmHg}$ & 0 & 0 \\
\hline & $>60 \mathrm{mmHg}$ & 0 & 0 \\
\hline
\end{tabular}

Các bệnh nhi được tái khám cho kết quả phẫu thuật tốt, không còn tăng áp phổi, van hai lá và van 3 lá hở mức độ nhẹ. Trong đó có 1 bệnh nhi có tình trạng hở hai lá mức độ trung bình cần phải theo dõi kỹ

\section{BÀN LUẬN.}

Chẩn đoán ban đầu của bệnh kênh nhĩ thất toàn phần thường là nhờ vào siêu âm tim. Siêu âm tim đặc biệt hữu hiệu để mô tả giải phẫu, các bệnh lý kèm theo có thể có. Trong 2 thập kỷ qua, sự hiểu biết về giải phẫu và hình thái học của kênh nhĩ thất toàn phần cộng với những tiến bộ 
trong kỹ thuật phẫu thuật đã làm giảm đáng kể tỷ lệ tử vong sau phẫu thuật. Can thiệp phẫu thuật ở bệnh nhân tốt nhất là từ 3 đến 6 tháng [10]. Sự chậm trễ của phẫu thuật trong bối cảnh này dần đến gia tăng tình trạng bệnh tật do viêm đường hô hấp, tăng mô van và biến dạng, và bệnh mạch phổi [4].

$\mathrm{Xu}$ hướng can thiệp sớm làm giảm tình trạng tăng áp phổi, là một trong những nguyên nhân chính gây nên tình trạng tử vong của bệnh cảnh [1], [11].

Tại trung tâm của chúng tôi việc phẫu thuật sớm đã giúp tránh tình trạng tăng áp phổi sau phẫu thuật, 4 bệnh nhân còn tình trạng tăng áp phổi trung bình thuộc nhóm bệnh nhân lớn hơn 6 tháng, điều này càng cho thấy sự cần thiết của việc phẫu thuật sớm kênh nhĩ thất toàn phần. Xơ hóa nội mạch phổi có thể được tìm thấy từ tháng thứ 6 trở đi [9].

Ngoài ra việc phẫu thuật sớm cũng giúp giữ được chức năng của các van nhĩ thất, việc sữa chữa các van nhĩ thất giai đoạn này thuận lợi hơn do chưa có sự giãn vòng van lớn [7].

Sau phẫu thuật được nhấn mạnh vào việc tối ưu hóa sản lượng tim và tránh cơn cao huyết áp phổi. Theo Edvin Prifti sử dụng oxit nitric trong tất cả các bệnh nhân có áp suất phổi lớn hơn $50 \%$ áp lực hệ thống khi kết thúc phẫu thuật. Sau mổ cần chú ý đến tình trạng thiếu oxy, tăng huyết áp, đau và hạ thân nhiệt là những yếu tố gây nên sự co thắt phổi.

Phẫu thuật sữa chữa van nhĩ thất ở kênh nhĩ thất toàn phần cần chú ý đến việc thiếu mô van dẫn đến hạn chế di động van nhĩ thất [8]. Trong nghiên cứu của chúng tôi tình trạng hở van nhĩ thất sau mổ cải thiện rõ rệt, cho kết quả khả quan. Trong các nghiên cứu khác đều đồng ý kỹ thuật 2 patch làm tôn trọng cấu trúc van, giảm việc thiếu mô van, giảm tình trạng hở van nhĩ thất tiến triển [3], [5].

Trong nghiên cứu của chúng tôi tỷ lệ rối loạn nhịp tim, block $\mathrm{A}-\mathrm{V}$ độ III là 4 bệnh nhân $(7,7 \%)$, điều này cũng tương đương với các trung tâm khác trên thế giới.
5 bệnh nhân( $9,6 \%$ ) tử vong, tất cả đều gặp ở bệnh nhân lớn tuổi, các bệnh nhi nhỏ tháng có thời gian hậu phẫu ngắn cũng như tiên lượng tốt hơn. Điều này cũng hợp lý do bệnh nhi lớn tuổi thường có tăng áp phổi nặng và mức độ hở van lớn và khó hồi phục [4].

\section{KẾT LUẬN}

Kênh nhĩ thất toàn phần là một trong những bệnh tim bẩm sinh phức tạp, bệnh nhi thường mắc kèm hội chứng Down. Việc chẩn đoán cũng như phương pháp phẫu thuật cần đòi hỏi phương tiện chẩn đoán hiện đại như MSCT, thông tim, chụp mạch. Việc phẫu thuật cần được thực hiện sớm $(<6$ tháng) từ lúc phát hiện để tránh tình trạng phát triển quá mức của tăng áp phổi, xơ hóa nội mạch phổi và giãn vòng van nhĩ thất. Kết quả phẫu thuật sữa chữa kênh nhĩ thất toàn phần cho kết quả tốt.

\section{TÀI LIÊU THAM KHẢO}

\section{Alexi-Meskishvili $\mathbf{V}$, Ishino $\mathbf{K}$,} Dähnert I, et al (1996), Correction of complete atrioventricular septal defects with the doublepatch technique and cleft closure, Ann Thorac Surg, 62, 519-25.

2. Bando K, Turrentine MW, Sun K, et al. (1995), Surgical management of complete atrioventricular septal defects. A twenty-year experience, J Thorac Cardiovasc Surg, 110, 1543-54.

3. Bogers AJJC, Akkersdijk GP, De Long PL, Henrich AH, Takkenberg JJM, Van Domburg RT, Witsenburg M (2000), Results of primary two-patch repair of complete atrioventricular septal defect, Eur J Cardiothorac Surg, 18, 473-9.

4. Edvin Prifti, PhD, Massimo Bonacchi, et al (2004), Repair of Complete trioventricular Septal Defects in Patients Weighing Less Than 5 kg, Ann Thorac Surg, 77, 1717-26.

5. Gunther T, Mazzitelli D, Haehnel CJ, Holper K, Sebening F, Meisner H (1998), Long-term results after repair of complete 
atrioventricular septal defects: analysis of risk factors, Ann Thorac Surg, 65, 754-60.

6. Hanley FL, Fenton KN, Jonas RA, et al. (1993), Surgical repair of complete atrioventricular canal defects in infancy, $J$ Thorac Cardiovasc Surg, 106, 387-97.

7. Michielon G, Stellin G, Rizzoli G, Casarotto DC (1997), Repair of common atrioventricular canal defects in patients younger than four months of age, Circulation, 316-22.

8. Najm HK, Coles JG, Endo M, Stephens D, Rebeyka IM, Williams WG, Freedom RM (1997), Complete atrioventricular septal defects: results of repair, risk factors, and freedom from re-operation, Circulation, 96, 829-35.
9. Newfeld EA, Sher M, Paul MH, Nikaidoh H (1977), Pulmonary vascular disease in complete atrioventricular canal defect, $\mathrm{Am} \mathrm{J}$ Cardiol, 39, 721-6.

10. Takaaki Suzuki, et al (2008), Results of Definitive Repair of Complete Atrioventricular Septal Defect in Neonates and Infants, Ann Thorac Surg, 86, 596-603.

11. Wetter J, Sinzobahamvya N, Blaschczok C, et al (2000), Closure of the zone of apposition at correction of complete atrioventricular septal defect improves outcome, Eur J Cardiothorac Surg, 17, $146 \quad-53$ 